\title{
Insurance, Racial/Ethnic, SES-Related Disparities in Quality of Care Among US Adults with Diabetes
}

\author{
Ruwei Hu • Leiyu Shi $\cdot$ Sarika Rane \\ Jinsheng Zhu $\cdot$ Chien-Chou Chen
}

Published online: 21 December 2013

(c) The Author(s) 2013. This article is published with open access at Springerlink.com

\begin{abstract}
Diabetes-related quality improvement initiatives are typically aimed at improving outcomes and reducing complications. Studies have found that disparities in quality persist for certain racial/ethnic and socioeconomically disadvantaged groups; however, results are mixed with regard to insurance-based differences. The purpose of this study is to investigate the independent associations between type of health insurance coverage, race/ethnicity, and socioeconomic status (SES), and quality of care, as measured by benchmark indicators of diabetesrelated primary care. This study used the Diabetes Care Survey of the 2010 Medical Expenditure Panel Survey. Bivariate and multivariate logistic regressions were used to examine the association between quality of diabetes care and type of insurance coverage, race/ethnicity, and SES. Multivariate analyses also controlled for additional demographic and health status characteristics. Respondents with insurance coverage (particularly those with private
\end{abstract}

\section{R. $\mathrm{Hu}$}

School of Public Health, and Center of Migrant Health Policy,

Sun Yat-sen University, Guangzhou, China

R. Hu $\cdot$ L. Shi $\cdot$ S. Rane $\cdot$ J. Zhu

Johns Hopkins Primary Care Policy Center, Baltimore, MD, USA

L. Shi

Health Policy and Health Services Research, Department of Health Policy and Management, Johns Hopkins University Bloomberg School of Public Health, Baltimore, MD, USA

\section{C.-C. Chen $(\bowtie)$}

Department of International Business, Ling Tung University, 1, Lingtung Road, Nantun, Taichung City 40852, Taiwan, ROC e-mail: chou5@teamail.ltu.edu.tw insurance or with Medicare and Medicaid coverage) were more likely to receive quality diabetes care than uninsured individuals. Few significant disparities based on race/ethnicity or SES persisted in subsequent multivariate analyses. Findings suggest that insurance coverage may make the greatest impact in ensuring equitable distribution of quality diabetes care, regardless of race/ethnicity or socioeconomic status. With the implementation of Affordable Care Act under which more people could potentially gain access to insurance, policymakers should next track insurance-based diabetes care disparities.

Keywords Primary care - Quality of care - Diabetes . Racial disparities

\section{Introduction}

Diabetes is one of the leading causes of morbidity and mortality in the United States (US), and represents an enormous public health and economic burden. Nearly 26 million people in the US have diabetes-a figure that continues to climb as the population ages and chronic conditions increase in prevalence [1, 2]. As of 2010, approximately $27 \%$ of adults ages 60 and older had diabetes, while 1.9 million adults ages 20 and older were newly diagnosed. Diabetes mellitus is the seventh leading cause of mortality in the US, and is associated with a number of health complications if preventive care and proper treatment is not received [3]. These complications can include renal disease, non-traumatic lower limb amputations, blindness, and increased risk for cardiovascular disease and stroke [1, 2, 4].

Evidence suggests that proper adherence to clinical guidelines for diabetes preventive care can reduce the risk 
of health complications in patients with diabetes, and improve long-term health outcomes [5]. The American Diabetes Association (ADA) established guidelines for processes of care in the preventive care of patients with diabetes; these guidelines include $\mathrm{HbA1c}$ testing at least twice per year, annual dilated eye examinations, and annual foot examinations [6]. In addition, the ADA and the National Cholesterol Education Program jointly established target clinical outcomes related to cardiovascular health, such as regular cholesterol testing. Meeting these targets can help patients reduce the risk of diabetic complications. For example, the ADA recommends that patients' HbA1c levels are less than $7 \%$, and that total cholesterol levels are less than $200 \mathrm{mg} / \mathrm{dl}$ [7].

Despite clinical advances that have been made with regard to effective prevention, diagnosis, and treatment of diabetes, certain groups shoulder a disproportionate burden of the disease. Studies have shown that those who are poor or who comprise racial/ethnic minority groups have a higher prevalence of diabetes and are more likely to suffer diabetes-related complications that require hospitalization than their non-poor and non-minority counterparts [8-14]. For example, an estimated $13.2 \%$ of non-Hispanic blacks and $11.9 \%$ of Hispanics have diabetes, compared with $7.1 \%$ for non-Hispanic whites $[1,2]$. Several studies have also shown that disadvantaged groups are less likely to receive diabetes-related preventive care [15-19]. Differences in diabetes-related outcomes may be partially attributable to disparate access to care, as determined by lack of insurance or inadequate insurance coverage, having unmet needs for medical care or prescription medication, or inconsistent access to a regular source of care or primary care provider [8, 9, 20, 21]. Non-Hispanic black and Hispanic populations in particular report inconsistent access to care, and barriers to obtaining health insurance, compared with white populations $[20,21]$.

The literature examining disparities in quality of diabetes care is mixed. Some previous studies, primarily using state and health systems data, suggested that racial/ethnic minority populations with diabetes receive lower quality care, compared with their white counterparts $[9,11,20-$ 22]. However, other studies using nationally-representative datasets have shown either narrowing gaps in disparities or no significant differences in quality of diabetes care between racial/ethnic minority groups and white patients [18, 23, 24]. Although studies have examined quality of care for diabetes, few studies have compared disparities beyond those that are associated with racial/ethnic group, such as socioeconomic status or insurance coverage [25]. Among those examining insurance and diabetes care, the insured were found to receive better quality of diabetes care than the uninsured, and those who were continuously insured received better care than those who were partially insured [26-29]. However, these studies were either based on older data or conducted in only one or a few states.

The purpose of this study is to address this gap in the literature, by assessing insurance, racial/ethnic, and SESrelated disparities in quality of diabetes care among US adults with diabetes. The unique contribution of this study lies in its use of a nationally-representative dataset and the inclusion of socioeconomic status (SES) in accounting for racial/ethnic and insurance-related disparities in diabetes care. The results of this study will provide up-to-date information on the topic and empirical evidence to lay the groundwork for tracking impacts of the implementation of the Affordable Care Act (ACA).

\section{Methods}

\section{Data Source}

Data for this study came from the 2010 Medical Expenditure Panel Survey (MEPS) — an annual nationally-representative survey of the non-institutionalized civilian population that has been administered jointly by the Agency for Healthcare Research and Quality (AHRQ) and the National Center for Health Statistics (NCHS) since 1996 [30]. The MEPS collects information from household respondents, providers, and employers in areas including health care utilization, medical expenditures, access to care, quality of care, and insurance coverage. It uses an overlapping panel design in which data are collected in five rounds of interviews over a 2.5 year period [31]. This study analyzed data from the 2010 MEPS Household Component; specifically, the Diabetes Care Survey that is periodically administered to household members who report having been diagnosed with diabetes and contains a total of nine survey items [32]. The 2010 MEPS contained a total of 32,846 observations; the current study used information from respondents aged 18 and over who completed the Diabetes Care Survey. These respondents were classified as diabetic if they reported being told by a clinician that they had diabetes. A total of 1,909 people with diabetes were included in the study, representing an estimated 20,970,670 adult population with self-reported diabetes. The overall response rate of MEPS for 2010 was $58.6 \%$ and the response rate for the Diabetes Care Survey was $90.1 \%$.

\section{Analytical Variables}

For this study, indicators of diabetes care (dependent variables) among household respondents were examined across insurance status, race/ethnicity, and SES (independent variables). Four measures of diabetes care were included in this study: (1) reported having a hemoglobin 
A1C measurement at least once in the past year, (2) reported having a blood cholesterol check in the past year, (3) reported having a retinal eye exam in the past year, and (4) reported having a foot examination in the past year. These measures were consistent with quality performance indicators endorsed by the National Quality Forum (NCQA) for adults aged 18-75 with diabetes [33].

Respondents' race/ethnicity was categorized as nonHispanic white, non-Hispanic black, Hispanic, and other. For people with multi-racial/ethnic origin, they were classified in the following order: Hispanic, black, and white. The 'other' category included Asians, American Indians and Alaskan Natives, and unspecified races. Since they all had relatively small sample size, they were grouped together in the analysis. Since the "other" group was so heterogenous, the results pertaining to this category were difficult to interpret and therefore not emphasized in the presentation of study findings and discussion.

Insurance status was categorized as uninsured, privatelyinsured, Medicare-insured, Medicaid-insured, and other publicly-insured. Categories of health insurance coverage were mutually exclusive. Persons with multiple types of health insurance were assigned to the first appropriate category in the following order: privately-insured, Medicare-insured, or Medicaid-insured, For example, the category 'privately-insured' included persons who had any type of private coverage either alone or in combination with other coverage. The category "Medicare-insured" included persons who had Medicare either alone or in combination with other public coverage. The category "Medicaid-insured", included persons who had Medicaid either alone or in combination with other non-Medicare, public coverage. Since the Diabetes Care Survey was a cross-sectional (one-time in 2010) survey, the insurance variable represented current status only.

SES was a composite variable comprising information from three separate measures: income, education, and employment. We used 'poverty status' to represent income and coded it as a dichotomous measure $(1=$ poor/near poor/ low-income; 2 = middle income/high income). We used 'highest education attained' to represent education and coded it as a dichotomous measure $(1=$ below bachelor which includes 'no degree,' 'GED,' or 'high school diploma'; 2 = bachelor or higher degree which includes 'bachelor's degree,' 'master's degree,' 'doctorate degree,' or 'other degree' defined in MEPS as an educational degree other than a bachelor's, master's, or doctorate degree.). We used 'employment status' to represent employment and coded it as a dichotomous measure ( $1=$ not employed; $2=$ employed). Although it was possible to have more detailed categories for these three measures, we chose to collapse into two categories per measure so that there would be enough sample (and power) per category in the combined measure of SES. The combined SES variable included four categories representing the gradient in SES, from best to worst: high-SES (with $2 \mathrm{~s}$ from all three SES measures), above-average SES (with $2 \mathrm{~s}$ from two of the three SES measures), below-average SES (with 2s from one of the three SES measures), and low-SES (with 1s from three SES measures).

In addition to these primary independent variables, a number of individual characteristics were measured as covariates based on their known association with use of health care services, including age (coded as a continuous measure), gender, marital status, self-reported health status (excellent/very good/good, fair/poor), limitations (i.e., selfreported impairments in activities of daily living), and geographical region (Northeast, Midwest, South, West).

\section{Statistical Analysis}

Data analysis was performed using SAS version 9.3 [34]. Due to the complex survey design employed in MEPS, all analyses included a design effect and sampling weights in order to ensure that the sample was nationally-representative of adults living in the United States with diabetes. First, descriptive statistics were computed for all variable included in the study to yield a profile of the study sample. Next, the distribution of quality of care indicators received by adults with diabetes was obtained for each racial/ethnic group, insurance status categorization, and SES level. Chi square $\left(\chi^{2}\right)$ tests were conducted to assess significant differences in quality of care across each of these three independent variables.

In addition, multivariate logistic regressions were used to examine quality of diabetes care. Models were adjusted for patients' insurance status, race/ethnicity, SES, age, gender, marital status, health status, presence of functional limitations, and geographic region. In order to estimate these relationships, odds ratios and $95 \%$ confidence intervals were calculated. For all analyses, a level of $\alpha<0.05$ was considered statistically significant.

\section{Results}

\section{Descriptive Results}

Table 1 provides descriptive results for all the variables included in the analysis. A total of 1,909 subjects with diabetes (weighted sample equals 20.9 million) were included in the analysis. Among the sampled adults with diabetes, approximately $89 \%$ reported having a hemoglobin A1C measurement at least once in the past year, $84 \%$ reported having a blood cholesterol check, $65 \%$ reported having a retinal eye examination, and $69 \%$ reported having a foot examination. 
Table 1 Characteristics of the study sample

\begin{tabular}{|c|c|c|}
\hline & \multicolumn{2}{|l|}{ Total } \\
\hline & Freq & Weighted freq $(\%, \mathrm{SE})$ \\
\hline Sample & 1,909 & $20,970,670$ \\
\hline \multicolumn{3}{|l|}{ Diabetes care } \\
\hline \multicolumn{3}{|c|}{$\begin{array}{l}\text { Adults age } 18 \text { and over with diabetes who reported having a } \\
\text { hemoglobin } \mathrm{A} 1 \mathrm{C} \text { measurement at least once in past year }\end{array}$} \\
\hline No & 154 & $1,488,476(10.33,1.01)$ \\
\hline Yes & 1,100 & $12,917,698(89.67,1.01)$ \\
\hline \multicolumn{3}{|c|}{$\begin{array}{l}\text { Adults age } 18 \text { and over with diabetes who reported having a blood } \\
\text { cholesterol check in past year }\end{array}$} \\
\hline No & 334 & $3,309,511(16.06,1.04)$ \\
\hline Yes & 1,538 & $17,293,946(83.94,1.04)$ \\
\hline \multicolumn{3}{|c|}{$\begin{array}{l}\text { Adults age } 18 \text { and over with diabetes who reported having a retinal } \\
\text { eye examination in past year }\end{array}$} \\
\hline No & 721 & $7,287,399(35.29,1.36)$ \\
\hline Yes & 1,153 & $13,360,820(64.71,1.36)$ \\
\hline \multicolumn{3}{|c|}{$\begin{array}{l}\text { Adults age } 18 \text { and over with diabetes who reported having a foot } \\
\text { examination in past year }\end{array}$} \\
\hline No & 615 & $6,457,397(31.37,1.24)$ \\
\hline Yes & 1,260 & $14,125,295(68.63,1.24)$ \\
\hline \multicolumn{3}{|l|}{ Insurance } \\
\hline Uninsured & 221 & $1,908,648(9.1,0.69)$ \\
\hline Medicaid & 262 & $2,176,448(10.38,0.79)$ \\
\hline Medicare & 499 & $5,155,017(24.58,1.2)$ \\
\hline Private & 894 & $11,388,888(54.31,1.46)$ \\
\hline Other public & 33 & $341,669(1.63,0.36)$ \\
\hline \multicolumn{3}{|l|}{ Race/ethnicity } \\
\hline White & 827 & $13,283,395(63.34,1.69)$ \\
\hline Black & 469 & $3,302,095(15.75,1.13)$ \\
\hline Hispanic & 442 & $2,913,117(13.89,1.23)$ \\
\hline Other & 171 & $1,472,062(7.02,0.94)$ \\
\hline \multicolumn{3}{|l|}{ SES measures } \\
\hline \multicolumn{3}{|l|}{ Poverty } \\
\hline Poor/near poor/low income & 862 & $7,545,882(35.98,1.51)$ \\
\hline Middle income/high income & 1,047 & $13,424,787(64.02,1.51)$ \\
\hline \multicolumn{3}{|l|}{ Education } \\
\hline Below bachelor & 1,605 & $16,735,710(80.26,1.21)$ \\
\hline Bachelor and higher degree & 292 & $4,117,048(19.74,1.21)$ \\
\hline \multicolumn{3}{|l|}{ Employment status } \\
\hline Not employed & 1,148 & $12,277,233(58.59,1.46)$ \\
\hline Employed & 759 & $8,678,267(41.41,1.46)$ \\
\hline \multicolumn{3}{|l|}{ SES composite } \\
\hline High SES & 148 & $2,070,328(9.94,0.87)$ \\
\hline Above-average SES & 512 & $6,431,076(30.86,1.39)$ \\
\hline Below-average SES & 619 & $7,046,991(33.82,1.2)$ \\
\hline Low SES & 616 & $5,289,193(25.38,1.28)$ \\
\hline \multicolumn{3}{|l|}{ Demographic measures } \\
\hline $\mathrm{Age}^{\mathrm{a}}$ & 1,909 & $60.56(0.37)$ \\
\hline \multicolumn{3}{|l|}{ Sex } \\
\hline Male & 844 & $10,258,465(48.92,1.3)$ \\
\hline
\end{tabular}

Table 1 continued

\begin{tabular}{lrr}
\hline & Total & \\
\cline { 2 - 3 } & Freq & Weighted freq $(\%$, SE $)$ \\
\hline Female & 1,065 & $10,712,204(51.08,1.3)$ \\
Marital status & & \\
Not married & 905 & $9,015,997(42.99,1.38)$ \\
Married & 1,004 & $11,954,672(57.01,1.38)$ \\
Health status & & \\
Excellent/VG/good & 1,180 & $13,535,960(64.58,1.49)$ \\
Fair/poor & 728 & $7,423,797(35.42,1.49)$ \\
Any limitation & & \\
No & 1,679 & $18,425,091(87.95,0.86)$ \\
$\quad$ Yes & 228 & $2,524,808(12.05,0.86)$ \\
Region & & \\
Northeast & 279 & $3,513,472(16.75,1.56)$ \\
Midwest & 387 & $4,642,834(22.14,1.16)$ \\
South & 815 & $8,725,989(41.61,1.73)$ \\
West & 428 & $4,088,375(19.5,1.22)$ \\
\hline
\end{tabular}

${ }^{a}$ Age results are mean (SE)

In terms of insurance status, $54.31 \%$ had private insurance, $24.58 \%$ had Medicare, $10.38 \%$ had Medicaid, $1.63 \%$ had other public insurance, but $9.1 \%$ were uninsured. In terms of race/ethnicity, $63.34 \%$ were non-Hispanic white, $15.75 \%$ black, $13.89 \%$ Hispanic, and $7.02 \%$ other. In terms of SES, $64.02 \%$ had middle- or highincome and $35.98 \%$ were poor, near poor, or of lowincome. For education, $19.74 \%$ had bachelor or higher degree and $80.26 \%$ had below-bachelor education. For employment, $41.41 \%$ were employed and $58.59 \%$ were unemployed (primarily due to the large proportion of the respondents who were retired). The composite SES variable showed $9.94 \%$ categorized as high SES, $30.86 \%$ above-average SES, $33.82 \%$ below-average SES, and $25.38 \%$ low SES.

In terms of demographic and health status characteristics, the mean age was $60.56,51.08 \%$ were females, $57.1 \%$ were married, $64.58 \%$ considered their health status to be excellent, very good, or good, $87.95 \%$ had no physical limitations, and the most likely place of residence was south (41.61\%), followed by Midwest (22.14\%), west $(19.5 \%)$, and northeast $(16.75 \%)$.

\section{Bivariate Results}

Table 2 displays the distribution of quality of care received by adults with diabetes; bivariate results are displayed by insurance type, race/ethnicity, and SES. The analysis found significant differences across insurance types for all four diabetes quality of care indicators $(p<0.001)$. Across three of the four quality indicators, adults covered by 


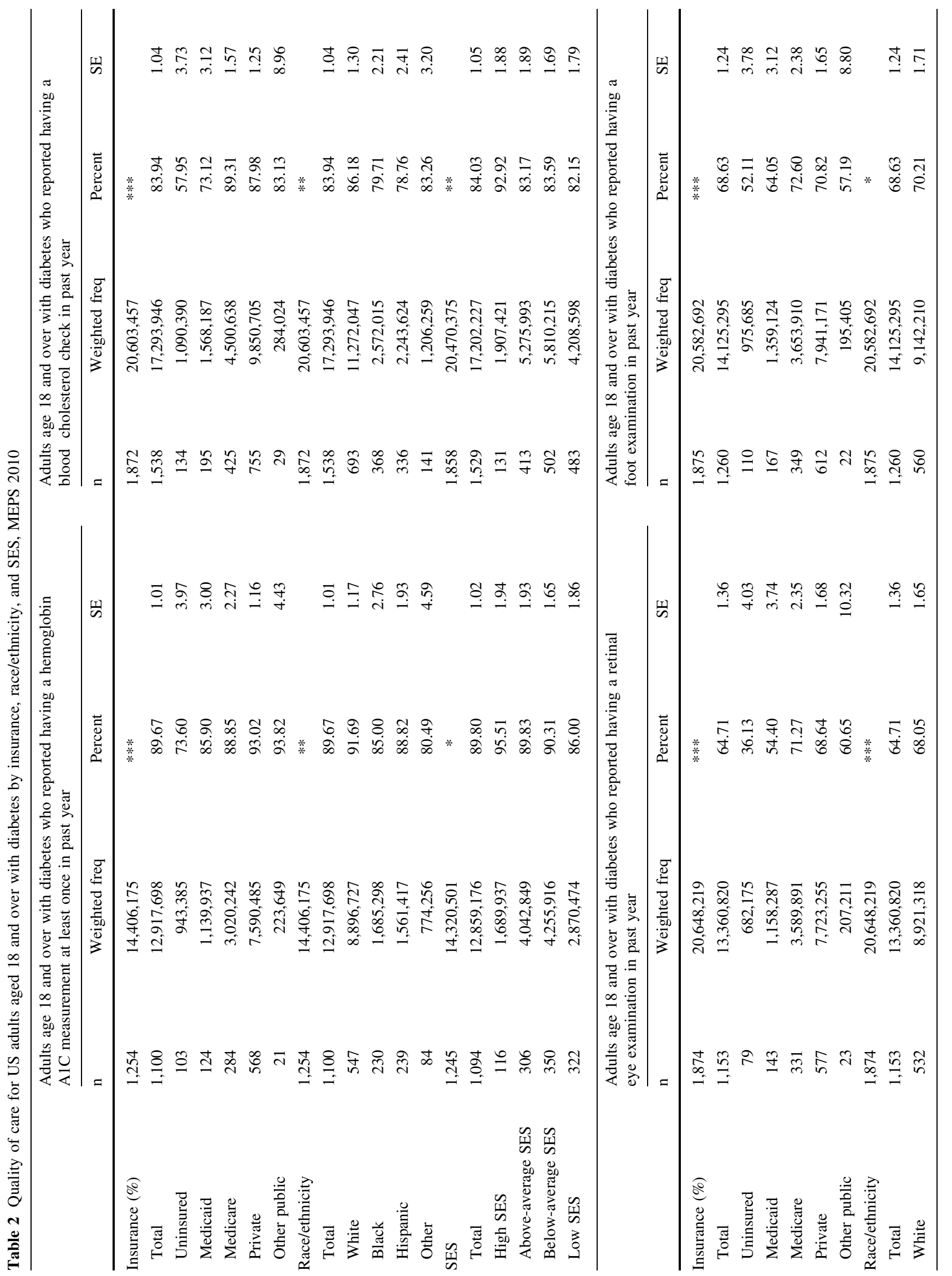




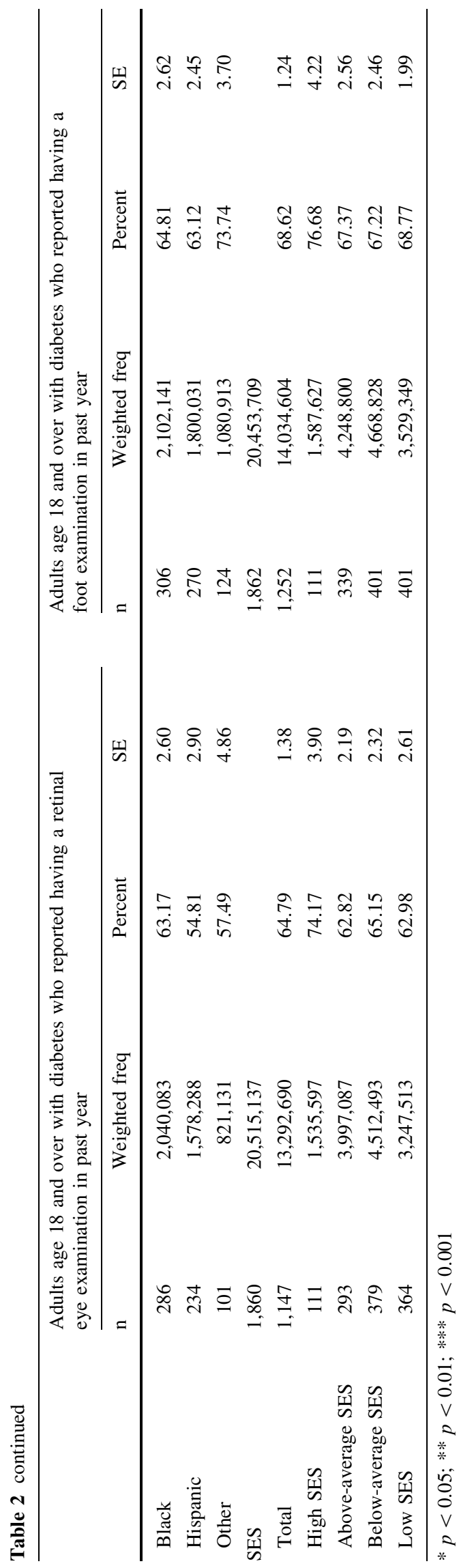

Medicare reported the highest rate of receipt of services, while adults with no insurance reported the lowest rate (89.3 vs. $57.9 \%$ reported having a blood cholesterol check, 73.5 vs. $36.1 \%$ reported having a retinal eye examination, and 72.3 vs. $52.1 \%$ reported having a foot examination). Adults who were privately insured reported the highest rate of receipt of a yearly hemoglobin A1C measurement $(93.02 \%)$, and the second highest rate of receipt across the remaining three quality indicators. Uninsured adults also reported the lowest rate of receiving a yearly hemoglobin A1C measurement $(73.6 \%)$.

Differences across racial/ethnic groups were also statistically significant for each of the four diabetes quality of care indicators. In three of the four quality of care categories, Hispanic adults reported the lowest rates of receiving diabetes services while non-Hispanic white adults reported the highest rates. With regard to having a hemoglobin A1C measurement, non-Hispanic white adults reported the highest rates $(91.7 \%)$ while those classified as 'other' (primarily Asians) adults reported the lowest rates (80.5\%). Among those who had blood cholesterol checked in the past year, non-Hispanic white adults reported the highest rate $(86.2 \%)$ while Hispanic adults reported the lowest rate $(78.8 \%)$. Rates of yearly retinal eye examinations were highest among non-Hispanic white adults (68\%) and lowest among Hispanic adults (54.8\%). Rates of yearly foot examinations were highest among 'other' adults with diabetes $(73.7 \%)$ and lowest among Hispanic adults $(63.1 \%)$.

With regard to differences across SES categories, bivariate findings were statistically significant for receipt of a hemoglobin A1C measurement $(p<0.05)$ and a blood cholesterol check in the past year $(p<0.01)$. The breakdown of results was unsurprising - across all four diabetes quality of care indicators, adults in the high SES category reported the highest rates of receipt while adults with low SES reported the lowest rates.

\section{Multivariate Results}

Table 3 presents the results of multivariate logistic regression models that explored the association between diabetes quality of care and health insurance, race/ethnicity, and SES, while adjusting for age, gender, marital status, perceived health status, functional limitations, and census region.

The analyses did find significant insurance-based disparities in quality of care indicators; respondents who were uninsured had lower odds of receiving diabetes services than privately insured patients, but there were few differences between privately insured patients and those with Medicaid, Medicare, or other public insurance. For example, compared to the privately insured, the uninsured had 
significantly lower odds of reporting having a hemoglobin A1C measurement in the past year $(0.205, p<0.001)$, having a blood cholesterol check $(0.259, p<0.001)$, having a retinal eye examination $(0.383, p<0.001)$, and having a foot examination (0.577, $p<0.01)$. Similar relationships were found between the uninsured and Medicare-insured (results not shown, but available upon request). Among the insured, only Medicaid-insured had lower odds of reporting having a blood cholesterol check in the past year when compared to the privately insured (0.502, $p<0.01)$.

The analyses found racial/ethnic disparities persisted in diabetes quality of care in only one of the four measures. Both non-Hispanic black and other minority adults had lower odds of reporting receiving a hemoglobin A1C measurement at least once in the past year compared with non-Hispanic white adults $(p<0.01)$.

The analyses also found some SES disparities on selected diabetes quality of care measures. Specifically, compared to the low SES group, the high SES group had significantly greater odds of reporting having a hemoglobin A1C measurement in the past year $(2.977, p<0.05)$ and having a blood cholesterol check $(2.567, p<0.01)$.

\section{Discussion}

This study used the most recently available MEPS data to explore the presence of disparities in quality of diabetes care, and to build on past research investigating whether racial/ethnic and sociodemographic differences in quality of care persist despite the implementation of quality improvement initiatives across the US [35, 36]. Based on the unadjusted results, we found that insurance coverage and race/ethnicity were significantly associated with having each of the four benchmark diabetes quality of care indicators within the past year-a hemoglobin A1C measurement, a blood cholesterol check, a retinal eye examination, and a foot examination. Similarly, SES was significantly associated with having a hemoglobin A1C measurement and having a blood cholesterol check.

After controlling for other demographic and health status characteristics, we found that the significant association between insurance coverage and quality of care remained. In other words, respondents who had some form of insurance (i.e., private insurance, Medicare, or Medicaid) were more likely to receive diabetes services than uninsured respondents across all four quality of care indicators. In contrast, most of the significant differences across quality of care based on race/ethnicity or SES level disappeared in the multivariate analyses-findings that are consistent with previous studies that have shown narrowing or no disparities based on race/ethnicity [18, 24, 37].
Our findings suggest that insurance coverage, rather than race/ethnicity or socioeconomic status, makes the greatest difference for ensuring that diabetes care meets minimum quality of care medical standards. These findings corroborate studies in the literature that point to insurance as an important factor in mitigating health and health care disparities between those groups who are socially disadvantaged versus others [25, 38]. Although some racial/ethnic and SES disparities in quality appear to persist, this study suggests that an expansion of different types of insurance coverage would make the biggest impact in terms of improving the quality of diabetes care and reducing the disproportionate burden of the disease and its complications.

Traditionally, public health practitioners used education campaigns to inform the public about health threats and how to avoid them. However, recent legislation and government regulation activities established a national framework that incorporates the obesity prevention goals and supports the use of policy and law to change social norms and reverse the obesity epidemic [39]. For example, the Patient Protection and ACA is an important step undertaken by the federal government to address health disparities. The legislation included provisions to expand prescription drug coverage for those covered under Medicare or other health plans. Furthermore, it contains a number of provisions aimed at reducing barriers to access for medically-underserved and disadvantaged populations, such as expanded access to primary and preventive care services through community health centers, premium and cost-sharing subsidies, and Medicaid expansions to provide coverage for more low-income individuals and families. In addition to the ACA, performance-based coverage models such as Accountable Care Organizations and Patient-centered Medical Home (PCMH) could make a positive impact to ensure that those with diabetes receive services that are proven to optimize health outcomes [40].

We must note several limitations of this study. First, study results are based on self-reported information from adult respondents and subject to recall bias and subsequent threats to reliability. Second the analysis was based on cross-sectional data, which only allows us to draw inferences of association rather than causation. However, our conclusions are strengthened by the strong survey design and nationally-representative sample of responses included in the analysis. Finally, this study examined diabetes quality of care based on four benchmark indicators of services received by respondents. It would have been useful to include variables that captured additional information on health care use and health status of respondents, such as accessibility of care, type of provider seen, frequency of health care use, or disease severity. Future analyses could be strengthened by such factors; however, 


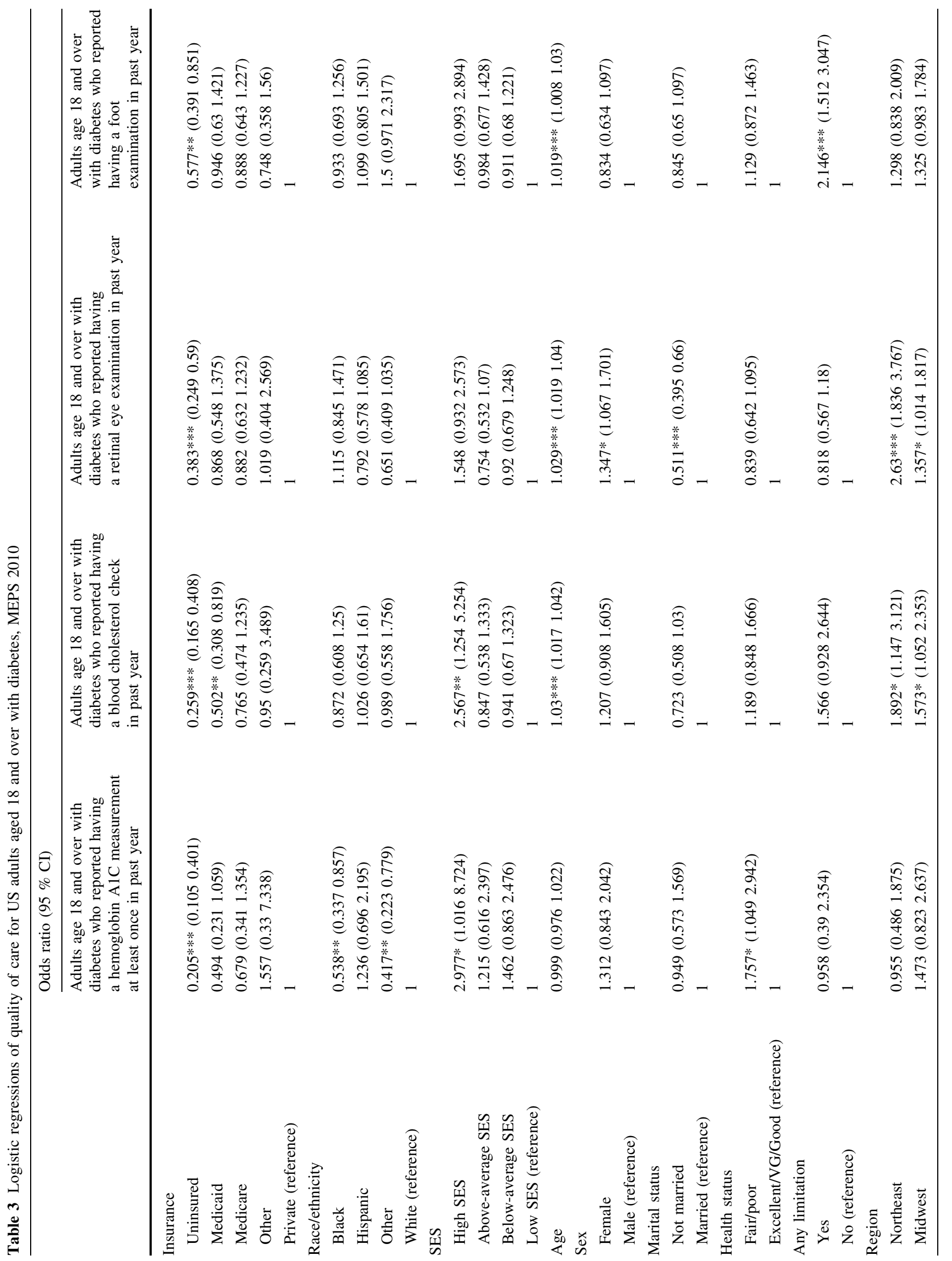


our inclusion of variables capturing self-reported health status and functional limitations helped mitigate this limitation.

In conclusion, this study strongly suggests that health insurance plays a large role in ensuring quality diabetes care and mitigating disparities based on race/ethnicity or socioeconomic status. Many quality improvement initiatives aimed at improving health outcomes are intended to address disparities by focusing on chronic illness such as diabetes - a strategy based on the fact that traditionally disadvantaged and underserved populations disproportionately carry the burden of diabetes and its complications $[35,41]$. However, health care providers and policymakers must recognize expanded or enhanced insurance coverage as an effective tactic in addressing barriers to accessing care, and improving the quality diabetes care and health outcomes. The ACA is moving towards the right direction as a legislation towards expanding insurance coverage and creating a regulatory engine that will work to move the US from a system that follows the customary care model of medical care toward an evidence-based system of medical care [42, 43], but great efforts need also be given to enhance quality care to those insured regardless of type of insurance coverage.

Acknowledgments The study is supported by Johns Hopkins Primary Care Policy Center and the Medical science Grants of Guangdong province, China: A2013177.

Conflict of interest There are no known conflicts of interest by all the authors of this paper.

Open Access This article is distributed under the terms of the Creative Commons Attribution License which permits any use, distribution, and reproduction in any medium, provided the original author(s) and the source are credited.

\section{References}

1. Centers for Disease Control and Prevention. Age-adjusted percentage of civilian, noninstitutionalized population with diagnosed diabetes, by race, United States, 1980-2009. Diabetes data and trends. US Department of Health and Human Services, Atlanta, GA. 2011. http://www.cdc.gov/diabetes/statistics/prev/ national/figbyrace.htm. Accessed Feb 12013.

2. Centers for Disease Control and Prevention. National diabetes fact sheet: general information and national estimates on diabetes in the United States. US Department of Health and Human Services, Atlanta, GA. 2011. http://www.cdc.gov/diabetes/pubs/pdf/ ndfs_2011.pdf. Accessed Feb 12013.

3. Kochanek KD, Xu J, Murphy SL, Miniño AM, Kung H. US Department of Health and Human Services. Deaths: preliminary data for 2009. Natl Vital Stat Rep. 2011;59(4):1-51.

4. McCollum M, Ellis SL, Morrato EH, Sullivan PW. Prevalence of multiple cardiac risk factors in US adults with diabetes. Curr Med Res Opin. 2006;22(6):1031-4.

5. The Diabetes Control and Complications Trial Research Group. Lifetime benefits and costs of intensive therapy as practiced in the 
diabetes control and complications trial. J Am Med Assoc. 1996;276:1409-15.

6. American Diabetes Association. Standards of medical care for patients with diabetes mellitus. Diabetes Care. 2002;25(1): 213-29.

7. American Diabetes Association. ADA clinical practice recommendations: executive summary: standards of medical care in diabetes-2010. Diabetes Care. 2010;33(Suppl 1):S4-5.

8. Smedley B, Stith A, Nelson A (eds). Unequal treatment: confronting racial and ethnic disparities in health care. Washington, DC: National Academy Press; 2002.

9. Heisler M, Smith DM, Hayward RA, Krein SL, Kerr EA. Racial disparities in diabetes care processes, outcomes, and treatment intensity. Med Care. 2003;41:1221-32.

10. Karter AJ, Ferrara A, Liu JY, Moffet HH, Ackerson LM, Selby JV. Ethnic disparities in diabetic complications in an insured population. J Am Med Assoc. 2002;287(19):2519-27.

11. Kirk JK, D'Agostino RB, Bell RA, Passmore LV, Bonds DE, Karter AJ, Narayan KM. Disparities in HbA1c levels between African-American and non-Hispanic white adults with diabetes: a meta-analysis. Diabetes Care. 2006;29:2130-6.

12. Krishna S, Gillespsie KN, McBride TM. Diabetes burden and access to preventive care in the rural United States. The Journal of Rural Health. 2010;26(1):3-11.

13. Lanting LC, Joung IM, Mackenbach JP, Lamberts SW, Bootsma AH. Ethnic differences in mortality, end-stage complications, and quality of care among diabetic patients: a review. Diabetes Care. 2005;28(9):2280-8.

14. Romero CX, Romero TE, Shlay JC, Ogden LG, Dabelea D. Changing trends in the prevalence and disparities of obesity and other cardiovascular disease risk factors in three racial/ethnic groups of USA adults. Adv Prev Med. 2012;2012:172423. doi:10. $1155 / 2012 / 172423$.

15. Andrus MR, Kelley KW, Murphey LM, Herndon KC. A comparison of diabetes care in rural and urban medical clinics in Alabama. J Community Health. 2004;29(1):29-44.

16. Centers for Disease Control and Prevention. Prevalence of receiving multiple preventive-care services among adults with diabetes-United States, 2002-2004. MMWR Morbid Mortal Wkly Rep. 2005;54(44):1130-3.

17. Harris MI. Racial and ethnic differences in health care access and health outcomes for adults with type 2 diabetes. Diabetes Care. 2001;24(3):454-9.

18. Lee JA, Liu CF, Sales AE. Racial and ethnic differences in diabetes care and health care use and costs. Prev Chronic Dis. 2006;3(3):A85.

19. LeMaster JW, Chanetsa F, Kapp JM, Waterman BM. Racial disparities in diabetes-related preventive care: results from the Missouri Behavioral Risk Factor Surveillance System. Prev Chronic Dis. 2006;3(3):A86.

20. Agency for Healthcare, Research and Quality. Access to health care. National healthcare disparities report. US Department of Health and Human Services, Rockville, MD. 2010. http://www. ahrq.gov/qual/nhdr10/Chap9.htm. Accessed Feb 12013.

21. Agency for Healthcare, Research and Quality. Effectiveness. National healthcare disparities report. US Department of Health and Human Services, Rockville, MD. 2010. http://www.ahrq.gov/ qual/nhdr10/Chap2.htm. Accessed Feb 12013.

22. Wilkes AE, Bordenave K, Vinci L, Peek ME. Addressing diabetes racial and ethnic disparities: lessons learned from quality improvement collaboratives. Diabetes Manag Lond Engl. 2011;1(6):653-60.

23. Bynum JP, Fisher ES, Song Y, Skinner J, Chandra A. Measuring racial disparities in the quality of ambulatory diabetes care. Med Care. 2010;48(12):1057-63.
24. Fisher ES, Goodman DC, Chandra A. Disparities in health and health care among Medicare beneficiaries: a brief report of the Dartmouth Atlas Project. Bronner KK (ed); 2008. http://www. dartmouthatlas.org/downloads/reports/AF4Q_Disparities_Report. pdf. Accessed Feb 12013.

25. Richard P, Alexandre PK, Lara A, Akamigbo AB. Racial and ethnic disparities in the quality of diabetes care in a nationally representative sample. Prev Chronic Dis. 2011;8(6):A142.

26. Gold R, DeVoe J, Shah A, Chauvie S. Insurance continuity and receipt of diabetes preventive care in a network of federally qualified health centers. Med Care. 2009;47(4):431-9.

27. Gold R, DeVoe JE, McIntire PJ, Puro JE, Chauvie SL, Shah AR. Receipt of diabetes preventive care among safety net patients associated with differing levels of insurance coverage. J Am Board Fam Med. 2012;25(1):42-9.

28. Nelson KM, Chapk MK, Reiber G, Boyko EJ. The association between health insurance coverage and diabetes care; data from the 2000 Behavioral Risk Factor Surveillance System. Health Serv Res. 2005;40(2):361-72.

29. Zhang JX, Huang ES, Drum ML, Kirchhoff AC, Schlichting JA, Schaefer CT, Heuer LJ, Chin MH. Insurance status and quality of diabetes care in community health centers. Am J Public Health. 2009;99(4):742-7.

30. Agency for Healthcare Research and Quality. MEPS data overview. US Department of Health and Human Services, Rockville, MD. http://www.ahrq.gov/research/data/meps/index.html. Accessed Feb 12013.

31. Cohen J. Design and methods of the medical expenditure panel survey household component. MEPS methodology report no. 2, AHCPR publication 97-0026. Agency for Health Care Policy and Research, Rockville, MD; 1997.

32. Agency for Healthcare Research and Quality. MEPS survey questionnaires. US Department of Health and Human Services, Rockville, MD. http://meps.ahrq.gov/survey_comp/survey.jsp. Accessed Feb 12013.

33. National Committee for Quality Assurance (NCQA). HEDIS measure development. US Department of Health and Human Services, Rockville, MD. http://www.ncqa.org/HEDISQualityMea surement/Research/HEDISMeasureDevelopment.aspx. Accessed Feb 12013.

34. SAS Institute. SAS (version 9.3) statistical software. Cary, NC: SAS Institute; 2011.

35. Chassin MR, Loeb JM, Schmaltz SP, Wachter RM. Accountability measures-using measurement to promote quality improvement. N Engl J Med. 2010;363:683-8.

36. Chin MH, Auerbach SB, Cook S, Harrison JF, Koppert J, Jin L, Thiel F, Karrison TG, Harrand AG, Schaefer CT, Takashima HT, Egbert N, Chiu SC, McNabb WL. Quality of diabetes care in community health centers. Am J Public Health. 2000;90: $431-4$.

37. Bynum JP, Bernal-Delgado E, Gottlieb D, Fisher E. Assigning ambulatory patients and their physicians to hospitals: a method for obtaining population-based provider performance measurements. Health Serv Res. 2007;42:45-62.

38. McWilliams JM, Meara E, Zaslavsky AM, Ayanian JZ. Differences in control of cardiovascular disease and diabetes by race, ethnicity, and education: U.S. trends from 1999 to 2006 and effects of Medicare coverage. Ann Int Med. 2009;150(8): 505-15.

39. Fry C. Reform, healthy cities: using law and policy to reduce obesity rates in underserved communities. Fordham Urban Law J. 2013;40(4):1265-321.

40. Fisher ES, McClellan MB, Bertko J, Lieberman SM, Lee JJ, Lewis JL, Skinner JS. Fostering accountable health care: moving forward in Medicare. Health Aff. 2009;28(2):w219-31. 
41. Blumenthal D, Kilo CM. A report card on continuous quality improvement. Milbank Q. 1998;76(4):625-48.

42. Utley ER. The affordable care act and health promotion: the role of insurance in defining responsibility for health risks and costs. Duquesne Law Rev. 2012;50(2):271-331.
43. Van Tassel K. Harmonizing the affordable care act with the three main national systems for healthcare quality improvement: the tort, licensure, and hospital peer review hearing systems. Brooklyn Law Rev. 2013;78(3):883-928. 